CENTRE for ECONOMIC

$P$ E R F O R M A N C E

CEP Discussion Paper No 1189

February 2013

A Trapped Factors Model of Innovation

Nicholas Bloom, Paul Romer, Stephen Terry and John Van Reenen 


\begin{abstract}
When will reducing trade barriers against a low wage country cause innovation to increase in high wage regions like the US or EU? We develop a model where factors of production have costs of adjustment and so are partially "trapped" in producing old goods. Trade liberalization with a low wage country reduces the profitability of old goods and so the opportunity cost of innovating falls. Interestingly, the "China shock" is more likely to induce innovation than liberalization with high wage countries. These implications are consistent with a range of recent empirical evidence on the impact of China and offers a new mechanism for positive welfare effects of trade liberalization over and above the standard benefits of specialization and market expansion. Calibrations of our model to the recent experience of the US with China suggests that there will be faster long-run growth through innovation in the US and that, in the short run, this is magnified by the trapped factor effect.
\end{abstract}

Keywords: Trade, innovation, China

JEL Classifications: O33, F16, O38, J33

This paper was produced as part of the Centre's Productivity and Innovation Programme. The Centre for Economic Performance is financed by the Economic and Social Research Council.

\title{
Acknowledgements
}

We would like to thank Ken Arrow, Robert Hall, Chad Jones, Pete Klenow, Edward Lazear, John Roberts, John Sutton and participants at LSE, Stanford and San Diego for helpful comments. Van Reenen would like to thank the ESRC for financial support through the Centre for Economic Performance.

Nicholas Bloom is an Associate of the Centre for Economic Performance, London School of Economics and Political Science. He is also a Professor of Economics at Stanford University. Paul Romer is a Senior Fellow in the Stanford Center for International Development (SCID) and the Stanford Institute for Economic Policy Research (SIEPR). Stephen Terry is a Graduate Student in the Department of Economics, Stanford University. John Van Reenen is the Director of the Centre for Economic Performance and Professor of Economics, London School of Economics and Political Science.

Published by

Centre for Economic Performance

London School of Economics and Political Science

Houghton Street

London WC2A $2 \mathrm{AE}$

All rights reserved. No part of this publication may be reproduced, stored in a retrieval system or transmitted in any form or by any means without the prior permission in writing of the publisher nor be issued to the public or circulated in any form other than that in which it is published.

Requests for permission to reproduce any article or part of the Working Paper should be sent to the editor at the above address.

(C) N. Bloom, P. Romer, S. Terry and J. Van Reenen, submitted 2013 
Recent empirical work has found that firms do more innovation when they are exposed to more low-cost import competition (Bloom, Draca and Van Reenen, 2012). Why is it that they innovate after something bad has happened to them? To explain this we add a natural friction to a model of growth and trade, an adjustment cost to reallocating factors of production between firms. These frictions can "trap" factors of production inside a firm that suffers from unexpected import competition. This reduces the opportunity cost of the inputs that the firm uses to innovate. Because the social return to innovation is higher than the private return, trade liberalization generates extra welfare benefits when this friction is present. Our finding that frictions can increase the welfare gains from a trade liberalization stands in contrast to the standard view that models which include such frictions reduce the gains from trade (e.g. Autor, Dorn and Hansen, forthcoming).

\section{Empirical Motivation}

Business case studies have long suggested that bad news in the form of increased import competition from low-cost countries can cause firms to "innovate or die." For example, Freeman and Kleiner (2005) describe how a US shoe maker responded to rising Chinese imports by halting production of mass-market men's shoes that were no longer profitable. Rather than simply idle its factory, skilled employees, brand capital and organizational resources, the firm introduced new types of shoes for smaller niche markets. One spe- 
cially designed batch of boots, run off for a local construction firm, had metal hoops in the soles that made it easier for workers to rapidly climb ladders. Making these boots took skilled engineers and R\&D. The new design earned a patent. Bartel, Ichinowski and Shaw (2007) report a similar story from US valve manufacturers. After losing the market for low-cost valves to Chinese competitors they switched to inventing and producing smaller runs of innovative valves.

\section{Figure 1: IT intensity grows with}

exposure to Chinese imports

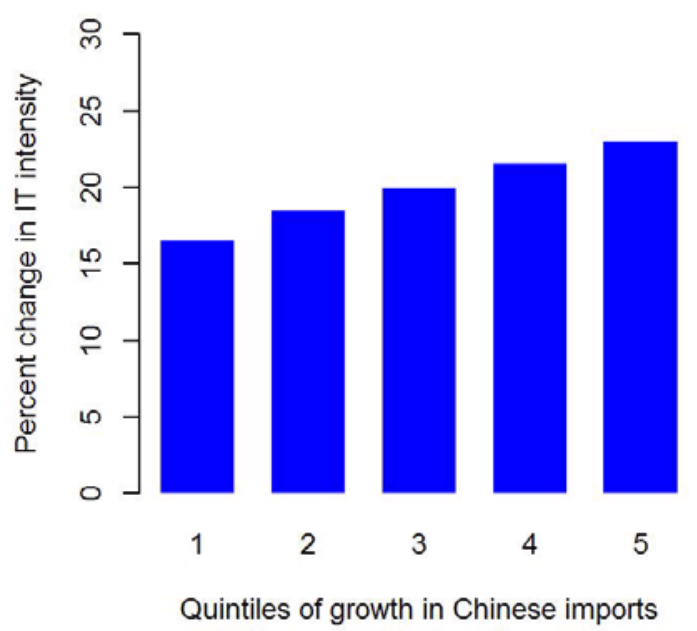

Note: Data from 23,000 firms across 12 European countries from 2000 to 2007. Source: Bloom, Draca and Van Reenen (2012). IT intensity defined as computers per employee, Chinese import growth defined as the change in China's share of all European imports.

The behavior reported in these case studies has also been confirmed in an econometric analysis on large panel data samples of firms in 12 European 
countries by Bloom, Draca and Van Reenen (2012). Firms that experienced a large increase in import competition after China's accession to the WTO rapidly increased their $R \& D$ expenditure, patenting and adoption of IT (see Figure 1). These changes were not merely the result of reallocation toward more innovative firms. Individual firms that faced more import competition exhibited a bigger increase in innovation. Nor did the results simply reflect the pro-innovation "escape competition" effects that arise in quality ladder models (e.g. Aghion, et al (2005)) as increased competition from high-cost OECD countries (like Japan) did not lead to a similar increase in innovation.

The first challenge that these results pose is to explain the difference in the behavior of an individual firm before and after a trade shock. Why is it that they innovate after something bad has happened to them? The usual presumption is that a negative shock will reduce investment, because it signals either lower expected returns or higher expected costs from more reliance on external finance. The second challenge is to explain the crosssectional difference in the behavior between firms after the shock hits. The move to a more open trade regime could raise the return to innovation, as models of trade and growth suggest. In this case, the incentive to innovate should be higher for all firms. Once again, the usual presumption would be that the firms that face a significant loss in revenue would be no more likely, and perhaps much less likely, to take advantage of the new opportunities. Why then do the results show just the opposite, that it is the firms that face more competition from imports that undertake relatively more innovation? 
The final challenge is why does this increase in innovation arise in response to low-cost export competition from China but not from high-cost export competition from countries like Japan?

The dynamic general equilibrium model fully developed with details available in Bloom, et. al. (2012) shows that adversity can indeed increase the rate of innovation if factors of production are trapped inside a firm. For the shoe company mentioned above, its workers might be trapped because they have human capital that is specific to the firm and which will be lost if they move to other firms. The firm's physical capital might also be costly to uproot and sell. After the trade shock reduces the price for one of the goods that the firm had been producing, the opportunity cost goes down for inputs that are trapped within the firm. The firm does more innovation, not because of an increase in the value of a newly designed good, but rather because of a fall in the opportunity cost of the inputs used to design and produce new goods.

\section{A Model of Growth and Trade}

Our model of growth extends the lab-equipment model of growth and trade proposed in Rivera-Batiz and Romer (1991), which builds on the closedeconomy model in Romer (1987). We assume a West-East model of the product cycle in which all innovation takes place in the West. (The West-East axis now seems a better way to capture trade flows between high- and lowwage countries than the traditional North-South axis.) Our extension allows 
not just for the extremes of autarky and free trade, but also for a continuum of intermediate degrees of trade integration indexed by a parameter $\phi$, which measures the fraction of goods that are allowed to trade freely. Consistent with previous results on growth and trade, an increase in trade integration $(\phi)$ raises the returns to innovation and increases the rate of growth of patents and the rate of growth of output, which benefits both regions.

Let $g(\phi)$ denote the steady-state growth rate associated with a given level of trade integration. We calibrate the model to the US experience in the last few decades and find that the increase in the growth rate associated with a change in $\phi$ is moderate. Increased trade with developing countries such as China could boost the worldwide steady-state growth rate by about 0.1 percentage points, so $g\left(\phi^{\prime}\right)-g(\phi) \approx 0.1 \%$. In our baseline this means that growth rises from 2.0 to 2.1 percentage points per annum.

For convenience, we work with an endogenous growth model in which a change in policy leads to this kind of change in the steady-state growth rate. We might instead have used a semi-endogenous model of the type proposed by Jones (1995b) in which policy changes induce long transitory changes in growth rates without changing the underlying steady-state growth rate. As Jones argues (1995a), this type of model provides a better fit to data over time horizons long enough to imply large changes in the stock of human capital, but there is little harm in assuming that the worldwide stock of human capital remains constant in the few years following a trade liberalization. Moreover, by making a small change in a single parameter, we could convert our model 
into a semi-endogenous model. By continuity, this small change would have little effect on our qualitative conclusions or numerical calculations.

To further limit the importance of any transition dynamics, we also minimize the persistence in the model. In particular, we assume that durable inputs in production last for only one period and that patents also last for only one period. With these assumptions, it takes only a few periods to converge to a new, slightly higher steady-state growth rate after an unexpected change in $\phi$.

\section{Trapped Factors}

To capture the cross-sectional result from Bloom, Draca and Van Reenen (2012), that firms faced with competition from a low-wage competitor do more innovation, we add adjustment costs that trap factors inside firms. Specifically, we assume that after a firm has acquired the factors that it will use in the current period, the government announces an increase from $\phi$ to $\phi^{\prime}$ that allows more imports from the low-cost East. We also assume that these imports compete with goods produced only by a subset of firms, so some firms experience more trade competition while others do not. Let $g^{S}$ ( $S$ for "Shock") denote the rate of growth of patents at firms that face this trade shock and let $g^{N}$ ( $N$ for "No shock") denote the growth rate of patents at firms that face no new competition for goods that they make. When the shock from $\phi$ to $\phi^{\prime}$ is announced for period $T$, we find that

$$
g_{T}^{S}\left(\phi^{\prime}\right)>g_{T}^{N}\left(\phi^{\prime}\right)>g(\phi)
$$


Moreover, the difference between the two types of firms is large. In our baseline model, the number of new patents developed by a representative $S$ firm that faces a shock jumps up to a level that is $15.1 \%$ higher than for an $N$ firm with no shock. This cross-sectional impact on patenting rates can be seen in Figure 2, which plots for each industry the flow of new patents in the trapped-factors environment. For convenience, we normalize the pre-shock patent flows to 1000 patents for each type of firm. The figure also shows the identical rate of growth of patents for the two types of firms when factors are fully mobile.

Figure 2: Industry patent flows increase with import exposure

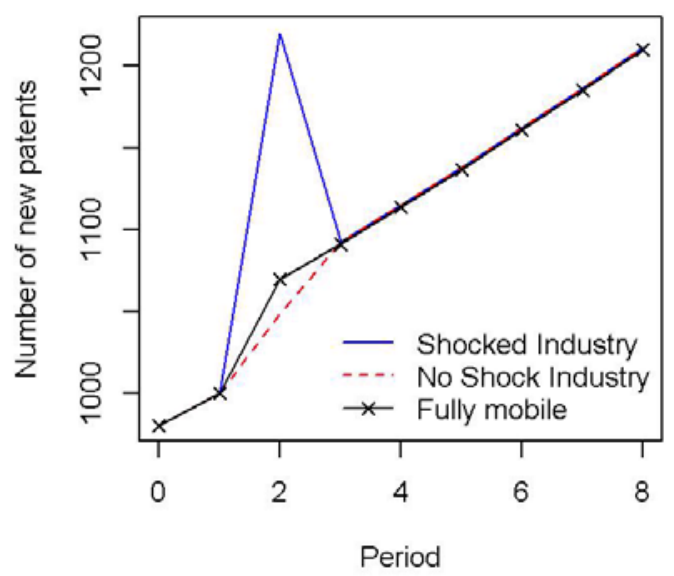

Note: A trade shock occurs in period 1. All results in this figure are produced using code available at http://www.stanford.edu/ nbloom/BRTV.zip.

To indicate the effect that the trapped factors and trade shock have on the aggregate rate of growth in the impact period which we denote by $T$ (period 
2 in the simulation in Figure 2), let $g_{T}^{\text {Trapped }}$ be the aggregate rate of growth of patents when factors are trapped and the trade shock is unanticipated. Let $g_{T}^{\text {Mobile }}$ denote the corresponding rate of growth when all factors are fully mobile. We find that

$$
g_{T}^{\text {Trapped }}>g_{T}^{\text {Mobile }}
$$

In our calibrated baseline, we observe a one-period growth boost $\left(g_{T}^{\text {Trapped }}-\right.$ $g_{T}^{\text {Mobile }} \approx 0.1 \%$ ). This means that in period $\mathrm{T}$ the growth rate is 2.2 percent per year, slightly higher than the new steady-state growth rate of 2.1 percent per year. In subsequent periods, the factors are no longer trapped so the growth rate returns quickly to the new steady-state value.

This one-period trapped-factors boost in the growth rate of patents causes a permanent increase in the stock of patents. Because the decentralized rate of innovation in such models is below the social optimum, the temporary boost in the growth rate and the permanent increase in the range of intermediate inputs induced by the interaction of trapped factors and the trade shock causes a correspondingly modest but positive increase in welfare in both the West and the East.

This type of welfare analysis of an unexpected, one-time policy change must of course be interpreted carefully. For example, if a partial trade liberalization today increases the expected probability of another liberalization in the future, firms would tend to reduce the inputs that they acquire to avoid the likelihood that they will face the private cost of being stuck with trapped factors when the next liberalization takes place. This would reduce 
the growth rate and thereby reduce welfare. For the same reason, if no frictions were present, it does not follow that a government could raise welfare by imposing costs that trap factors in firms. Any attempt at trapping factors inside firms at some future date will induce an offsetting reduction in factor demands by firms.

\section{Magnitudes of Trapped-Factor Approaches}

The magnitudes of the growth and welfare effects identified here are also sensitive to a crucial parameter in the model. For a calibrated version of a model like this to fit actual data, there must be some short-run decreasing returns in the technology that converts inputs into new patents. Increasing the quantities of inputs that are devoted to innovation in a period by some factor $\lambda$ should not lead to an increase in the number of patents by the same factor. Following Jones and Williams (2000), we assume that patents increase instead by the factor $\lambda^{1 / 2}$. A simple way to understand the source of these diminishing returns is to think of innovation as a search process. If a larger team is engaged in search, the difficulties of coordinating the search effort means that there is a higher probability that different groups make redundant discoveries. With two independent discoveries of something like a long-lasting light bulb, the number of new goods goes up by only one.

The key issue here is whether the challenge of avoiding redundant discoveries is entirely internal to a firm or extends across firms. It will be largely internal if different firms naturally specialize in separate parts of search space. 
It will be at least partly external to an individual firm if firms tend to search in the same parts of search space. Patent race models typically assume the extreme case of costs that are entirely external, in which case the production function for new designs exhibits a form of Marshallian external diminishing returns.

To capture the entire range of possibilities, the model allows for a parameter $\eta$ that indexes the continuum of possibilities ranging from fully internal to fully external costs. The baseline specification described above, has $\eta=1$, which implies that the costs are fully internal. In an alternative specification that allows for external costs, the magnitude of the trapped-factors boost to growth should be smaller because the higher research costs (or equivalently the lower productivity of research) caused by more innovation at the shocked firms leads to an increase in the innovation cost at the no-shock firms, hence a reduction in the innovation they undertake. For example, in a specification that allows for $\eta=0.5$, hence a 50-50 split between internal and external costs, we find that the magnitude of the difference $g_{T}^{\text {Trapped }}-g_{T}^{\text {Mobile }}$ is about half as large as in our baseline.

The analysis of technology spillovers provided by Bloom, Schankerman and Van Reenen (forthcoming) cannot reject the hypothesis that the costs of innovation are fully internal, so we use the value $\eta=1$ in our benchmark model. It is important, nevertheless, to recognize that the implications of the model are sensitive to this parameter and that we do not have a precise estimate of its value. 
We conclude that the model suggests the combination of trapped factors and asymmetric trade shocks causes a modest boost to welfare and growth, but quantifying this effect with precision requires much more work.

\section{$5 \quad$ Micro Evidence and Macro Effects}

We close with a discussion of what one could infer about aggregate effects from a microeconomic analysis like the one undertaken by Bloom, Draca and Van Reenen (2012). As applied to data generated by our model, their approach would involve running a regression of the log of the number of new patents developed by the two types of firms on year dummies that pick up the trends and a shocked-firm dummy that picks up the difference between the $S$ (shocked) and $N$ (non-shocked) firms. Using data from the model, this regression would show a higher rate of patenting for the $S$ firms in the impact period, $T$.

With large numbers of firms and no other macro shocks, this difference could be precisely estimated. The year dummies could also be used to estimate the aggregate impact - they would have magnitudes that grow at the rate $g(\phi)$ before the shock, $g_{T}^{N}\left(\phi^{\prime}\right)$ during the impact period, and $g\left(\phi^{\prime}\right)$ after the shock. However, other factors (such as business-cycle fluctuations) can cause year-to-year changes in the rate of innovation, so the year effects from the micro analysis are unlikely to yield reliable direct evidence about the aggregate effect on growth of the increased trade with China.

Nevertheless, the micro-evidence on the cross-sectional differences $g_{T}^{S}-g_{T}^{N}$ 
does provide important guidance about the structure of the general equilibrium model that describes the economy, and this model can then be used to infer what the aggregate growth effect might be. In this sense, our conclusion is more positive about the value of micro evidence in predicting aggregate behavior than the conclusions reached, for example, by Arkolakis, Demidova, Klenow and Rodríguez-Clare (2008), Atkeson and Burstein (2010) and Arkolakis, Costinot and Rodríguez-Clare (2012).

\section{Conclusions}

We build a standard model of endogenous growth and trade, providing a tight link between trade liberalizations and increases in the long-run growth rate. Motivated by empirical evidence which suggests that increased low-cost import competition stimulated innovation at affected firms, we incorporate short-run trapped factors which prevent movement of inputs across firms. Reductions in the opportunity cost of fixed inputs at shocked firms in the period of a trade liberalization yield an increase in innovative activity at those firms using these inputs. The presence of trapped factors leads to a permanent increase in the level of patents or varieties in the economy, as well as output and consumption, relative to an economy without adjustment costs, as well as an increase in welfare, suggesting that models ignoring trapped factors underestimate the gains from trade liberalization. 


\section{$7 \quad$ References}

Autor, David, David Dorn, and Gordon H. Hanson. Forthcoming. "The Geography of Trade and Technology Shocks in the United States." American Economic Review Papers and Proceedings.

Aghion, Philippe, Nicholas Bloom, Richard Blundell, Rachel Griffith and Peter Howitt. 2005. "Competition and Innovation: An Inverted-U Relationship." Quarterly Journal of Economics 120(2): 701-28.

Arkolakis, Costas, Arnaud Costinot and Andrés Rodríguez-Clare. 2012. "New Trade Models, Same Old Gains?" American Economic Review 102(1): 94-130.

Arkolakis, Costas, Svelenta Demidova, Peter Klenow and Andrés Rodríguez-Clare. 2008. "Endogenous Variety and the Gains from Trade." American Economic Review Papers and Proceedings 98 (4): 444-50.

Atkeson, Andrew and Ariel T. Burstein. 2010. "Innovation, Firm Dynamics, and International Trade." Journal of Political Economy 118(3): 433-84.

Bartel, Ann, Casey Ichinowski and Kathryn Shaw. 2007. "How Does Information Technology Really Affect Productivity? Plant-level Comparisons of Product Innovation, Process Improvement and Worker Skills." Quarterly Journal of Economics 122 (4): 1721-58.

Bloom, Nicholas, Mirko Draca and John Van Reenen. 2012. "Trade Induced Technical Change? The Impact of Chinese Imports on In- 
novation, IT, and Productivity." Unpublished.

Bloom, Nicholas, Paul M. Romer, Stephen J. Terry and John Van Reenen. 2012. "A Trapped Factors Model of Innovation." Unpublished.

Bloom, Nicholas, Mark Schankerman and John Van Reenen. Forthcoming. "Identifying Technology Spillovers and Product Market Rivalry." Econometrica.

Freeman, Richard B. and Morris M. Kleiner. 2005. "The Last American Shoe Manufacturers: Decreasing Productivity and Increasing Profits in the Shift from Piece Rates to Continuous Flow Production." Industrial Relations 44(2): 307-30.

Jones, Charles I. 1995a. "Time Series Tests of Endogenous Growth Models." Quarterly Journal of Economics 110(2): 759-84.

Jones, Charles I. 1995b. "R\&D-Based Models of Economic Growth." Journal of Political Economy 103(4): 759-84.

Jones, Charles I. and John C. Williams. 2000. "Too Much of a Good Thing? The Economics of Investment in R\&D." Journal of Economic Growth 5(1): 65-85.

Romer, Paul M. 1987. "Growth Based on Increasing Returns due to Specialization." American Economic Review Papers and Proceedings 77(2): $56-62$.

Rivera-Batiz, Luis and Paul M. Romer. 1991. "Economic Inte-gration and Endogenous Growth." Quarterly Journal of Economics 106(2): 531-55. 


\section{CENTRE FOR ECONOMIC PERFORMANCE Recent Discussion Papers}

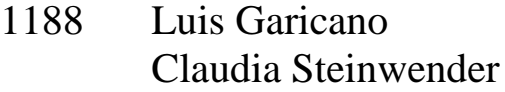

1187 Alex Bryson

George MacKerron

1186 Guy Michaels

Ferdinand Rauch

Stephen J. Redding

1185 Nicholas Oulton

María Sebastiá-Barriel

1184 Xuepeng Liu

Emanuel Ornelas

1183 Marc J. Melitz

Stephen J. Redding

1182 Fabrice Defever

Alejandro Riaño

1181 Wenya Cheng

John Morrow

Kitjawat Tacharoen

$1180 \quad$ Yona Rubinstein

Dror Brenner

1179 Martin Gaynor

Carol Propper

Stephan Seiler

1178 Philippe Aghion

Antoine

Dechezleprêtre

David Hemous

Ralf Martin

John Van Reenen

1177 Tim Butcher

Richard Dickens

Alan Manning

1176 Jan-Emmanuel De Neve Andrew J. Oswald
Survive Another Day: Does Uncertain

Financing Affect the Composition of

Investment?

Are You Happy While You Work?

Task Specialization in U.S. Cities from 18802000

Long and Short-Term Effects of the Financial Crisis on Labour Productivity, Capital and Output

Free Trade Aggreements and the

Consolidation of Democracy

Heterogeneous Firms and Trade

China's Pure Exporter Subsidies

Productivity As If Space Mattered: An

Application to Factor Markets Across China

Pride and Prejudice: Using Ethnic-Sounding

Names and Inter-Ethnic Marriages to Identify

Labor Market Discrimination

Free to Choose? Reform and Demand

Response in the English National Health

Service

Carbon Taxes, Path Dependency and Directed Technical Change: Evidence from the Auto Industry

Minimum Wages and Wage Inequality: Some Theory and an Application to the UK

Estimating the Influence of Life Satisfaction and Positive Affect on Later Income Using Sibling Fixed-Effects 
1175 Rachel Berner Shalem Francesca Cornaglia Jan-Emmanuel De Neve

1174 Monika Mrázová J. Peter Neary

1173 Nattavudh Powdthavee

1172 Gianluca Benigno Huigang Chen Christopher Otrok Alessandro Rebucci

Eric R. Young

1171 Ana Damas de Matos

1170 Bianca De Paoli Pawel Zabczyk

1169 Mirabelle Muûls

1168 Thomas Sampson

1167 Jérôme Adda

1166 Jonathan Wadsworth

1165 Nattavudh Powdthavee James Vernoit

1164 Natalie Chen

Dennis Novy

1163 Jörn-Stephan Pischke Hannes Schwandt

1162 Cletus C. Coughlin Dennis Novy
The Enduring Impact of Childhood on Mental Health: Evidence Using Instrumented CoTwin Data

Selection Effects with Heterogeneous Firms

Resilience to Economic Shocks and the Long Reach of Childhood Bullying

Optimal Policy for Macro-Financial Stability

The Careers of Immigrants

Policy Design in a Model with Swings in Risk Appetite

Exporters, Importers and Credit Constraints

Brain Drain or Brain Gain? Technology

Diffusion and Learning On-the-job

Taxes, Cigarette Consumption, and Smoking Intensity: Reply

Musn't Grumble. Immigration, Health and Health Service Use in the UK and Germany

The Transferable Scars: A Longitudinal Evidence of Psychological Impact of Past Parental Unemployment on Adolescents in the United Kingdom

On the Measurement of Trade Costs: Direct vs. Indirect Approaches to Quantifying Standards and Technical Regulations

A Cautionary Note on Using Industry Affiliation to Predict Income

Is the International Border Effect Larger than the Domestic Border Effect? Evidence from U.S. Trade

The Centre for Economic Performance Publications Unit

Tel 02079557673 Fax 02074040612

Email info@cep.lse.ac.uk Web site http://cep.lse.ac.uk 